\title{
Research on Quality Evaluation and Promotion Strategy of Digital Economy Development
}

\author{
Ling Wei \\ School of Economics, Anhui University of Finance \& Economics, Bengbu, China \\ Email: weiling19992017@126.com
}

How to cite this paper: Wei, L. (2020) Research on Quality Evaluation and Promotion Strategy of Digital Economy Development. Open Journal of Business and Management, 8, 932-942. https://doi.org/10.4236/ojbm.2020.82058

Received: February 24, 2020

Accepted: March 27, 2020

Published: March 30, 2020

Copyright (C) 2020 by author(s) and Scientific Research Publishing Inc. This work is licensed under the Creative Commons Attribution International License (CC BY 4.0).

http://creativecommons.org/licenses/by/4.0/

(c) (i) Open Access

\begin{abstract}
The digital economy is the trend of global economic development in the future. The development of the digital economy not only highly reflects the five development concepts of China, but also deepens the supply-side structural reforms and promotes the implementation of innovation-driven development strategies, thereby improving China's Competitive new advantages. After understanding the current status of domestic digital economy research, this article combines the connotation and characteristics of the digital economy, selects basic indicators from three dimensions of technology, economy, and environment, constructs an evaluation index system, and studies the quality of China's digital economy development from 2009 to 2018. The shortcomings of China's current digital economy development are analyzed, and effective promotion strategies are provided, in order to promote high-quality growth of the digital economy.
\end{abstract}

\section{Keywords}

Digital Economy, Development Quality, Principal Component Analysis, Promotion Strategies

\section{Introduction}

The term "digital economy" was first proposed by Tapscott Don of the United States in 1996. In the following two decades, the network infrastructure construction has been continuously upgraded, the level of information processing technologies such as big data and the Internet has gradually improved, and the global digital economy has been developed. The trend is fast. In recent years, China has also paid more and more attention to the development of the digital economy. In the report of the $19^{\text {th }}$ National Congress of the Communist Party of China, it was explicitly proposed to build a "digital China". At present, the new 
economic form of the digital economy has penetrated into all walks of life and fundamentally changed the development environment and activity forms of economic society. The digital economy is the trend of future economic development. It is a strong driving force to deepen supply-side structural reforms and reduce the gap between China and developed countries. However, the development of China's digital economy is in its infancy. How to promote the rapid development of China's digital economy Good development is a key issue that needs to be resolved in the construction of a "digital China" in the new era.

\section{Significance of Promoting the Development of the Digital Economy}

\subsection{Highly Reflect the Five Development Concepts}

China has proposed the five development concepts of "innovation, coordination, greenness, openness, and sharing". The development of the digital economy highly reflects our development philosophy. The digital economy is a new type of economic form, a product of the development requirements of the current era, and fully reflects the innovative development concept. Digital information is a new production factor in the digital economy era. Compared to labor, land, and capital, digital information is easier to achieve reasonable allocation among different regions. At the same time, driven by digital information, labor and capital will also. Transfers between regions have occurred to achieve coordinated regional development. With the increase in the penetration of the Internet and the strengthening of data processing technology, commodity trading locations have gradually shifted from offline to online, reducing the use of resources and improving the utilization of resources; at the same time, more low-carbon and environmentally-friendly industries Produced in the environment has greatly promoted the green development of our economy. The development of the digital economy has strengthened the trade between countries in the international market, increased the export targets of China's commodities, and further improved China's level of opening up. The digital economy is developed based on data information. Data information can be shared through the Internet. All industries and industries can adjust industry development trends in a timely manner based on the shared data information.

\subsection{Deepen Supply-Side Structural Reforms}

The development of the digital economy provides a starting point for adjusting the economic structure, optimizing the allocation of resources in agriculture, industry, and service industries, and creating new industrial chains and new business models. The development of the digital economy has accelerated the digital transformation of various industries, which has a greater impact on the development of agriculture, industry and service industries.

First, the digital economy is conducive to promoting the transformation of agricultural production. In the process of planting crops, digital information 
technology is used to monitor soil quality and environmental climate, and to choose the right time for planting. Use digital equipment to automatically monitor the growth of crops, reduce human labor and increase crop yields. In the aquaculture process, digital technology is used to monitor water quality and growth space in real time, and effectively manage the quantity of aquaculture. Increase aquatic resources. During the livestock breeding process, the health status of livestock and poultry is digitized, and a livestock information resource database is established to reduce the incidence of livestock and poultry. Combining agricultural production with digital information technology to realize automatic planting of crops, real-time monitoring of the growth environment of aquatic products, and accurate detection of the health of poultry and animals.

Second, the digital economy is conducive to improving the quality of industrial production. At present, China's industrial products are mainly produced by laborers and machines, but in most industrial enterprises, laborers are the main productivity of industrial products, so product quality is easily affected. With the development of the digital economy, digital information technology and industrial production are combined. On the one hand, industrial production is transformed into automation and intelligence to realize large-scale production of products and improve production speed and quality; Accurate docking, providing personalized customization services, and expanding the scale of industrial development.

Finally, the digital economy is conducive to generating new service models. With the trend of information networking and digitalization, digital services such as online registration, online payment, smart travel, and online shopping have developed rapidly, providing convenience for people to live, eat, live, and travel, and increasingly rely on digital services for daily life.

\subsection{Promote the Implementation of the Innovation-Driven Development Strategy}

The impact and change of the booming digital economy on China is a powerful manifestation of innovation-driven development. With the establishment and improvement of digital platforms, China has made significant progress in all aspects of development. First, China's economic development has given birth to new business models. China's future economic development will no longer rely on labor or resources to promote it, but instead will take innovation as the main driving force for economic development. The rise of the e-commerce industry is based on information digitization and big data analysis. The development of digital information technology has changed the original commodity transaction mode, directly connected producers and consumers, reduced transaction costs, and increased commodity transaction volume and transaction value. The second is to improve the quality of life of residents. Driven by the digital economy, residents can pay for their lives online, make appointments for appointments, and ask questions about illnesses, and enjoy services without leaving home. Third, 
the overall education level has been improved. Limited teaching resources and weak teachers in rural areas are the main reasons for the low level of education of rural residents. The application of networked teaching can effectively solve the problem of education development in rural areas, improve the imbalance of education development, and improve the overall education level. This shows that the digital economy promotes the implementation of China's innovation-driven development strategy and improves the quality of development in all aspects.

\subsection{Improve China's New Competitive Advantage}

The digital economy is bound to be a new trend in global economic development. At present, China has an advantage in this regard. Digital service systems in education, medical care, people's livelihood and other aspects are gradually improving, especially in mobile payment, both in terms of payment security, operability, and application coverage are far ahead of other countries. In this era of information digitization, competition between nations will evolve into competition for digital economic capabilities. Internet infrastructure construction, digital information processing capabilities, and integration of digital technologies and industries will all affect the development of a country's digital economy. Therefore, China must seize the new competitive advantages of the information digital era, vigorously promote the development of the digital economy, strengthen the integration of digital technology with various industries, increase the application rate of digital equipment, further open the digital gap with other countries and maintain a leading position and competitive advantage.

\section{Research Status of Digital Economy}

The digital economy, as a new economic form based on big data, has a significant impact on the quality of economic growth, industrial upgrades, structural reforms, and the development of new formats. The digital economy has not only attracted the attention of the country, but also attracted the attention of many scholars. Most scholars conduct research around the digital economy.

Tian Li pointed out that countries around the world have different understandings of the connotation of the digital economy, and the focus of developing the digital economy will also be different. Therefore, there are obvious differences in the development goals and strategies of the digital economy [1]. Cao Zhengyong realized that the development of the digital economy would lead to the transformation of China's industrial development model, reshape the value chain of the manufacturing industry, and thus change the mode of economic growth. After researching the digital technology and manufacturing development model, four new models to improve the quality of manufacturing development are proposed: intelligent production and manufacturing model, networked collaborative manufacturing model, personalized customization model, and service-oriented manufacturing model [2]. Cai Yuezhou distinguished the 
concept of the scale and increment of the value added of the digital economy, and measured the value added of the digital economy in various countries and their contribution to GDP growth [3]. Li Ping believes that the development of the digital economy should be divided into three stages: e-commerce, Internet +, and the transition to digitalization has begun. At different development stages of the digital economy, new business models have emerged, but new business models pose a huge challenge to China's tax system. After studying the taxation governance of new business models in various countries in the world, the taxation governance model of China under the digital economy is proposed [4]. Xu Ji and Tang Qi believe that the digital economy has caused errors in China's national economic accounting. New products, new consumption models, and new income affect consumption accounting in the national economic accounting system. Intangible assets and new investment affect investment accounting in the national economic accounting system. Cross-border flows based on knowledge assets and cross-border e-commerce affect import and export accounting [5]. Gu Tianlong pointed out that the digital economy has led to the construction of new engineering disciplines. China's higher education must change the educational goals and education models for talent training, cultivate new types of talents in line with the development of the digital economy, and improve digital quality [6].

To sum up, Chinese scholars carry out multi-level and multi-angle research on the digital economy in different fields. The research of most scholars is mainly divided into two aspects. One is to focus on the integration of digital economy with traditional industries, and the problems and challenges faced in the process of integration; the other is to focus on the changes of the new industry chain and new business model to the existing system under the development of digital economy. So far, domestic and foreign scholars have studied more about the development and changes in various fields under the influence of the digital economy, but less research on the digital economy itself. Therefore, on the basis of grasping the connotation and nature of the digital economy, this article studies the quality of the development of the digital economy in China, analyzes the problems existing in the development of the digital economy at this stage, and provides a reference strategy for the development of the digital economy into the fast lane as soon as possible.

\section{Empirical Research on the Quality of Digital Economy Development}

\subsection{Connotation and Characteristics of the Digital Economy}

The digital economy takes digital information as the main production factor, and uses the Internet platform to apply digital information processing technologies such as big data and cloud computing to digitize economic activities and economic environments. The digital economy is dominated by the three laws of Metcalfe's Law, Moore's Law, and Davido's Law, and it exhibits features such as 
convenience, high permeability, virtuality, directness, externality, and low cost.

\subsection{Constructing a Quality Evaluation System for the Development of the Digital Economy}

In order to understand the current state of the development of China's digital economy, this article selects basic indicators from three dimensions of science, technology, economy and environment, uses the principal component analysis method to evaluate the quality of China's digital economy development, and explores the problems existing in the development process of digital economy.

\subsubsection{Index Selection}

The changes brought about by the development of the digital economy to China are more obvious in terms of science and technology, economy and environment. First of all, although the digital economy is a product of the development of science and technology, the digital economy will also promote the development of science and technology. The new economic form of the digital economy can only be realized by relying on various digital information processing technologies. The rapid development of the digital economy will enable China to vigorously strengthen the construction of information technology and thereby promote scientific and technological progress. Secondly, the digital economy itself is an economic form, and the new business models and new industrial chains that it has spawned have a direct impact on China's economic development. In terms of measuring the quality of the digital economy, the current state of China's economic development has the most say. Finally, economic development needs to consider coexistence with the environment and ensure sustainable development, taking environmental development as one of the indicators to measure the quality of the digital economy. Therefore, this article regards these three aspects as the secondary indicators of the evaluation system, and selects the basic indicators on this basis.

In terms of scientific and technological indicators, this article selects five basic indicators: Internet penetration rate, mobile payment utilization rate, number of websites, fiber optic cable length, and Internet broadband access ports. In terms of economic indicators, this article chooses e-commerce transaction value, agricultural product transaction value, and technology. Market turnover, online retail market transactions as a percentage of GDP, and consumer price index and retail price index of the six basic indicators; In terms of environmental indicators, this article selects the rate of domestic garbage harmless treatment, industrial pollution treatment investment proportion, Four basic indicators are the proportion of investment in environmental pollution and the rate of urban sewage treatment.

\subsubsection{Evaluation System Construction}

According to the selected indicators, the evaluation system constructed in this paper is shown in Table 1. 


\subsection{Data Analysis}

This article selects the data from 2009-2018 to study the quality of digital economy development. After the data is dimensionless processed with SPSS software, the basic indicators are linearly combined using the principal component analysis method based on the correlation matrix to calculate the index value of the secondary indicator, and the principal component analysis is performed on the secondary indicator to measure the development of the digital economy Quality indicator value. Table 2 shows the weights of secondary indicators and the quality indicators of digital economy development.

According to the data in Table 2, the three secondary indicators of technology, economy, and environment have the same change trend as the quality of the

Table 1. Quality evaluation system for digital economy development.

\begin{tabular}{|c|c|c|}
\hline $\begin{array}{l}\text { Comprehensive } \\
\text { indicators }\end{array}$ & $\begin{array}{l}\text { Secondary } \\
\text { indicators }\end{array}$ & Basic indicators \\
\hline \multirow{15}{*}{$\begin{array}{l}\text { Digital Economy } \\
\text { Development Quality }\end{array}$} & Technology & Internet Penetration Rate (\%) \\
\hline & & Mobile payment utilization rate (\%) \\
\hline & & Number of websites per capita (per 10,000 people) \\
\hline & & Cable length $(\mathrm{km})$ \\
\hline & & $\begin{array}{l}\text { Broadband Internet access port per capita (person/10,000 } \\
\text { persons) }\end{array}$ \\
\hline & Economy & Proportion of e-commerce transactions in GDP (\%) \\
\hline & & $\begin{array}{l}\text { Proportion of agricultural products traded as a percentage of } \\
\text { GDP }(\%)\end{array}$ \\
\hline & & Technology market turnover as a percentage of GDP (\%) \\
\hline & & Online retail market transactions as a percentage of GDP (\%) \\
\hline & & Consumer Price Index \\
\hline & & Commodity retail price index \\
\hline & Environment & Harmless treatment rate of domestic garbage (\%) \\
\hline & & Proportion of investment in industrial pollution control (\%) \\
\hline & & $\begin{array}{l}\text { Proportion of investment in environmental pollution } \\
\text { treatment }(\%)\end{array}$ \\
\hline & & Urban sewage treatment rate (\%) \\
\hline
\end{tabular}

Table 2. Quality of digital economy development from 2009 to 2018.

\begin{tabular}{ccccccccccc}
\hline Year & 2009 & 2010 & 2011 & 2012 & 2013 & 2014 & 2015 & 2016 & 2017 & 2018 \\
\hline Technology & -2.24 & -2.32 & -1.81 & -1.07 & -0.53 & -0.19 & 0.97 & 1.87 & 2.45 & 2.86 \\
Economy & -3.38 & -2.72 & -1.97 & -1.10 & -0.37 & 0.33 & 0.99 & 1.75 & 2.48 & 4.00 \\
Environment & -2.30 & -1.81 & -1.23 & -0.79 & -0.76 & -0.51 & 0.87 & 1.61 & 2.29 & 2.63 \\
Quality of Digital & -4.57 & -3.96 & -2.89 & -1.71 & -0.96 & -0.21 & 1.63 & 3.02 & 4.17 & 5.48 \\
Economy Development & & & & & & & & & & \\
\hline
\end{tabular}


development of the digital economy, and the contributions of the three indicators of technology, economics, and environment to the quality of the development of the digital economy are roughly equivalent. The changing trend and contribution have also verified the rationality of the digital economy development quality evaluation system constructed in this paper. In addition, the data reflects that the quality of China's digital economy development has improved rapidly in the past decade, but compared with developed countries in the same period, China's digital economy development is slightly inferior, indicating that there are still some breakthrough points in the development of the digital economy.

\section{Challenges in the Development of the Digital Economy}

\subsection{Low Digital Quality of Workers}

In the process of integrating digital technology with traditional industries, the low digital quality of workers severely hinders the development of the digital economy. According to data from the National Bureau of Statistics, China's Internet penetration rate has reached $59.6 \%$ in 2018 , which is far from the Internet penetration rate of developed countries. The low Internet penetration rate indicates that most workers have lower digital quality, have less contact with Internet devices, and lack Internet skills. In the transition from traditional industries to digital development, on the one hand, digital production will replace the positions of low-quality laborers, causing most of the workers engaged in simple and repetitive jobs to lose their jobs; on the other hand, there is a lack of high-quality digital labor capable of using digital production equipment. This has led to slow progress in the digital transformation of the industry.

\subsection{Unbalanced Development of the Digital Economy}

On the one hand, the digital economy is developing unevenly across regions. Affected by the degree of urban and rural development, the two also differ in the level of network infrastructure construction. The development of urban digital economy is significantly better than that in rural areas. On the other hand, the development of the digital economy is uneven among the primary, secondary and tertiary industries. The tertiary industry develops rapidly, but it develops slowly in agriculture and industry. Whether it is the development scale of the e-commerce industry, or the promotion of digital public services such as intelligent travel, illness consultation, and online education, it has demonstrated the active development of the digital economy in the tertiary industry. However, in the development of agriculture and industry, the two take labor and capital as the main factors of production, coupled with the application of digital technology and less investment in digital facilities, resulting in a low degree of integration of digital technology with agriculture and industry, resulting in the digital economy affecting the three industries. There is a significant gap in the contribution of output value. It is this unbalanced development of the digital economy 
that has reduced the quality and speed of digital economy development.

\subsection{Information Security Risks}

User concerns about the leakage of personal information are a key factor limiting the development of the digital economy. On the one hand, e-commerce platforms such as Taobao and JD.com and mobile payment applications such as Alipay and WeChat require real-name registration. Users have doubts about the security of the existing personal information security system and are concerned about the leakage of their personal information, leading to digital applications. The penetration rate is not high. On the other hand, criminals use APPs to collect and steal user information and conduct online fraud, which has a wide range of adverse effects, causing users to resist the use of digital applications. The hidden danger of information security seriously affects the promotion and use of digital applications among residents and hinders the development of digital economy.

\section{Promotion Strategy for Digital Economy Development}

Aiming at the current status and challenges of the development of China's digital economy, this article provides improvement strategies from the aspects of strengthening network infrastructure construction, increasing data resources, improving the digital quality of the entire population, ensuring information security, and improving the legal and regulatory system to improve the quality of China's digital economy.

\subsection{Improve the Level of Network Infrastructure}

On the one hand, we will strengthen the construction of network infrastructure in rural areas, increase the number of Internet broadband access ports and the coverage of fiber optic cables, increase rural residents' awareness and use of the Internet, and bridge the "digital divide" between urban and rural areas. On the other hand, according to the needs of rural residents, develop digital applications suitable for rural residents, with the goal of improving the quality of life of residents and convenience of life, so that people's daily lives cannot be separated from digital applications. In order to solve the spatial imbalance in the development of the digital economy, different regions and different classes can enjoy the fruits of the development of the digital economy.

\subsection{Increase Data Resources}

The development of the digital economy is based on digital information as the main production factor. The quantity of digital information and the accuracy of digital information determine the development of the digital economy. Currently, the publicly available databases and the limited data stored in the databases hinder the development of the digital economy. To this end, China should establish a database containing digital information in various fields to ensure the ac- 
curacy and timeliness of digital information. At the same time, it will explore the operation mode of large-scale data collection, screening, and arrangement, establish a data sharing and exchange platform, promote the open sharing of data resources, and realize the high-quality development of the digital economy.

\subsection{Improve the Digital Quality of the Entire Population}

First, the government combined effective digital applications with current high usage rates to effectively publicize residents and raise their awareness of the digital economy. Secondly, for low-income and low-education workers, digital knowledge and digital skills training will be conducted to improve the digital quality of workers and reduce the number of unemployment in the process of digital transformation of the industry. Finally, colleges and universities should combine the development requirements of the digital economy, speed up the upgrading of talent training programs, integrate the digital economy with related majors, and cultivate high-quality digital talents in the digital age of information.

\subsection{Improve the Legal and Regulatory System}

The digital economy is a product of the era of digital information development. The development model, development momentum, and development factors are all different from the agricultural and industrial economies. Existing laws and regulations need to be "legal reform and abolition" based on the characteristics of the development of the digital economy. First, formulate relevant laws and regulations around digital information, information disclosure, data ownership, etc., and fill the gaps in the existing laws and regulations system. Second, make changes to existing tax policies. On the one hand, it provides tax policy support for the development of China's digital economy; on the other hand, it formulates a tax system for new business models to prevent tax evasion and evasion, which creates a bad atmosphere for the development of the digital economy. Finally, without infringing the interests of various subjects and affecting the development of related industries, the laws and regulations restricting the development of the digital economy are repealed.

\subsection{Improve Information Assurance Security}

The disadvantage of digitizing information is that it is easy to cause information leakage, which is also a concern of users of most digital applications. To promote the development of the digital economy, China must establish a sound information security system. On the one hand, it is necessary to formulate a strict information confidentiality system and increase the supervision of information to prevent personal information from being intentionally leaked by e-commerce platforms and mobile payment platforms. On the other hand, layers of protection walls are set up for information, and the information security system is checked from time to time to find loopholes in the information security system and repair them in a timely manner. Only by improving the information security 
system can we increase the utilization rate of digital applications and promote the development of the digital economy.

\section{Conflicts of Interest}

The author declares no conflicts of interest regarding the publication of this paper.

\section{References}

[1] Tang, Q. (2019) A Review of Literature on Digital Economy and National Economic Accounting. Economic Developments, 10, 117-131.

[2] Gu, T. (2019) Construction of New Engineering Subjects from the Perspective of Digital Economy. Teaching in China University, No. 6, 12-15.

[3] Cai, Y. (2018) Estimation of Value Added and Contribution of Digital Economy: Historical Evolution, Theoretical Basis and Methodological Framework. Qiushi Journal, No. 5, 65-71.

[4] Li, P. (2018) Analysis on Tax Governance of New Business Model under Digital Economy. International Taxation, No. 5, 16-19.

[5] Cao, Z. (2018) Research on New Manufacturing Modes to Promote the High Quality Development of China's Industry under the Background of Digital Economy. Theoretical Discussion, No. 2, 99-104.

[6] Tian, L. (2017) Comparative Study on the Concepts of Digital Economy in Various Countries. Reference for Economic Research, 40, 101-106+112. 